parations for the woolly aphis. I have always thought there might bo some field of usefulness for these preparations, as dips for this pest.

A MEMBer: Mr. President, last year part of our trees were dipped in a tobacco preparation for the woolly aphis and for the green aphis on the tops. We expect to dip about 20,000 this year. I hope that Mr. Parrott will try it. We are not certain how effective it is.

Mr. Hitchings: Last week a gentleman came to me and asked if he would be allowed to bring scions from an infested district to Maine, as he wished to use them to graft his trees. He wanted to secure seyeral thousand. Would it be safe to have these scions dipped or should they be fumigated?

A Member: Fumigated every time, I should say. ED.]

[The remainder of the Proceedings will appear in the next issue.-

\title{
THE LIFE HISTORY OF THE ARGENTINE ANT
}

\section{Iridomyrmex humilis Mayr}

By Wilamon Newell

A general account of this species and its habits appeared in the Journal of Economic Entomologx, Vol. I, p. 21 to 34 and accounts of two inquilines occurring in its nests were given in the same volume, p. 262. On p. 289-293, Mr. E. Foster published an interesting account of the introduction of this ant into New Orleans.

The present paper is intended to deal only with the more salient features of this insect's life history which have been brought to light in the course of the author's studies during the past two years.

There are but three adult forms in the case of this ant, the queen, male and worker. Of the immature forms there are three, egg, larva and pupa, of each the queen, male and worker. There is hardly sufficient difference between the virgin queen and the deälated queen after fertilization to justify considering them as distinct forms. A possible fourth stage may be recognized in the "callow," which is the term used by some writers in referring to the worker which has completed its transformation from pupa to adult but which has not attained the normal worker color and activity. A complete colony. may therefore consist of queen and workers only, of queens and workers or of queen (or queens), males and workers: with each of these combinations may be associated any one or all of the three immature stages corresponding to each of the three adult forms, or 
nine immature stages in all. Plate 5 shows a colony consisting of one queen, about 100 workers and about 20 eggs, with no larvæ, pupre or males present.

In size the colonies may vary from a dozen to many thousands of individuals and the number of queens present in a colony may vary from one to many hundreds. Though the Argentine ant is particularly aggressive and a hard fighter when coming in contact with most other species of ants, there is no apparent antagonism between separate colonies of its own kind. In fact, in heavily infested areas the workers and queens are so intermingled that the individuality of colonies is entirely lost sight of and all colonies appear to become part and parcel of one enormous "community." In this respect the species may be said to have a more perfect social organization than even the honeybees, colonies of which are very distinct and the individuals of which repel with alacrity any visitor from another colony.

\section{Methods of Study}

When the study of this ant was undertaken two requisites presented themselves, a form of artificial formicary in which continuous observations could be made and individuals kept track of from the time of egg deposition until the adult stage was reached, and some method by which all individuals of a colony could be confined to their own formicary.

Artificial formicaries, or cages, of various types were made and tried. Among them were cages consisting of two glass cylinders placed one within the other, the intervening space filled with sois, the Janet cage, molded of plaster of Paris and having several compartments, and wooden and glass cages constructed in the form of cubes, from which the ants could not escape. None of these met the requirements. In the cylindrical cages crumbling earth often destroyed the galleries and it was impossible to so regulate the space between cylinders that the ants could not construct invisible galleries into which eggs and larve were carried.

The Janet cages proved successful only in the case of very large colonies, but in these the multiplicity of individuals made accurate observations impossible. It may be remarked that this type of cage is excellent for studying the community life as a whole and for making experiments with poisons or with parasitic fungi or bacteria.

Cages totally enclosed were not successful for the reason that the ants, when deprived of the privilege of leaving their nest, failed to act in a normal manner.

The cage finally adopted was, with modifications, the one described 
by Sir John Lubbock on pages 2 and 3 of his classic work. ${ }^{1}$ This consists essentially of two glass plates, contrining between them a layer of pulverized earth in which the ants may burrow at their pleasure. Considerable difficulty was experienced in getting the glass plates the proper distance apart: if too for apart the ants could make burrows which were not open to observation and if too close together insufficient room was afforded the queen in which to stand and walk upright. As the queen is about twice as tall as the worker it seemed for a time that a suitable cage could not be constructed.

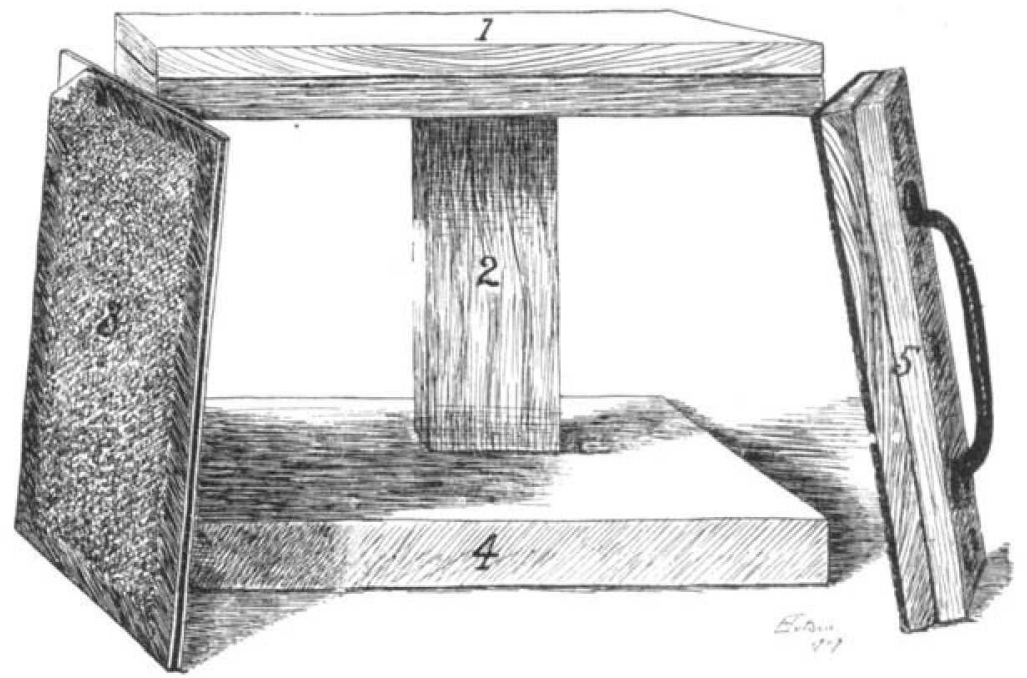

Fig. 1.-Artificial formicary or cage used in studying the Argentine ant: 1, supporting platform; 2 , standard; 3 , cage proper, made of glass and leather, containing earth; 4 , base; 5 , cover.

After repeated trials, however, it was found that if the space between the glass plates were made exactly $1.75 \mathrm{~mm}$. the queen would have sufficient room and the workers could not construct invisible galleries.

This type of cage and its supporting stand are well illustrated by Figures 1 and 2 . Figure 1 shows the several parts of the cage; " 3 " is the cage proper, consisting of two plates of glass held uniformly $1.75 \mathrm{~mm}$. apart by strips of leather at all four edges, a door or opening being left at one corner (See Figure 3). Old negatives, the films removed with caustic soda, have been found the most desirable for making these cages, both because such glass is remarkably clear and free from imperfections and because it is of uniform thickness. The

'Arebury.-"Ants, Bees and Wasps," 1881. 
size of the cage may vary from $31 / 4 \times 41 / 4$ up to $8 \times 10$ inches or even larger. Leather was found more satisfactory for malking the edges of the cage than either glass or wood. The strip of leather betweeen the glass margins is about $1 / 2$-inch in width. It is extremely difficult to find a strip of glass uniformly $1.75 \mathrm{~mm}$. thick and it is also diffcult to firmly attach one piece of glass to another. Wooden strips present the disadvantage of quickly decaying and of warping, no matter what glue or cement is used to hold them in position. Since

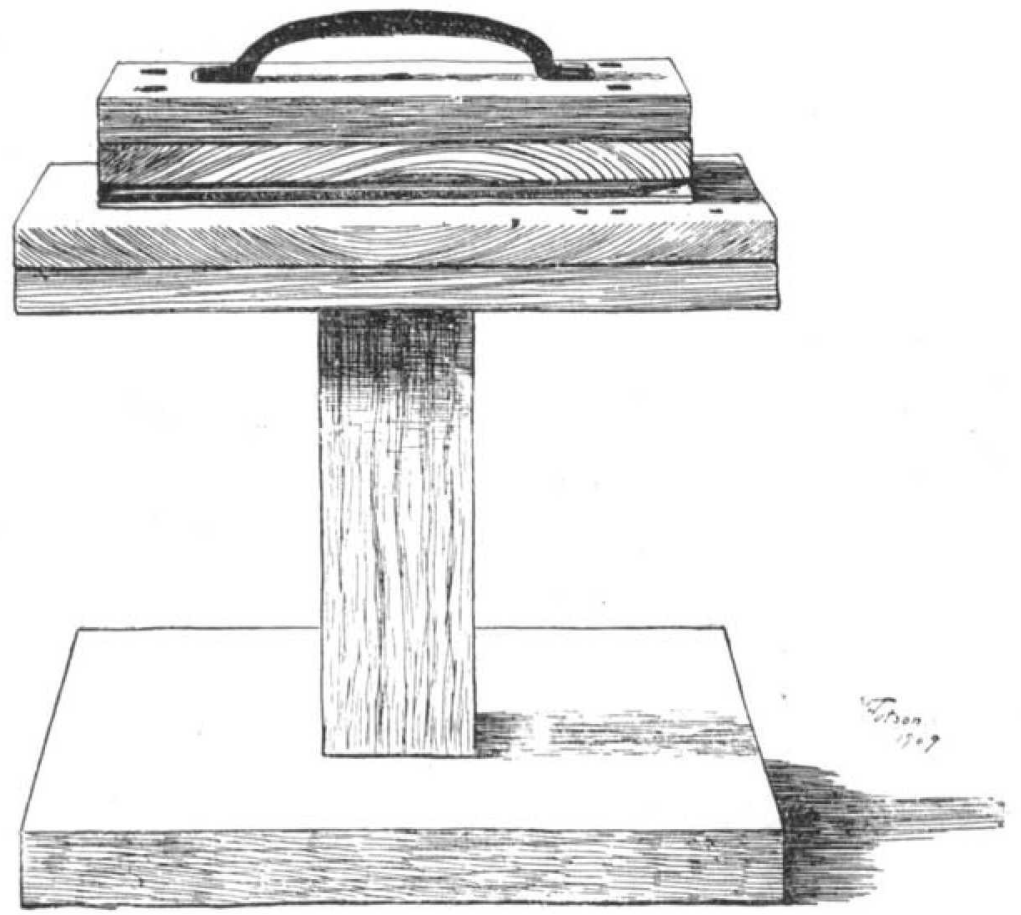

Fig. 2.-Artificial formicary with parts assembled ready for use.

it is sometimes desirable to place moist earth in the cages, or to add moisture from time to time, a waterproof cement is most desirable for attaching the glass plates to the leather strip. For this purpose the cement known as coaguline has been found satisfactory. The space between the glass plates is filled with finely pulverized earth, after completion and drying of the cage, and in this the ants are permitted to burrow and construct galleries as they please.

The cage proper is supported on a platform (1) which in turn rests firmly upon a standard (2) having a base (4). The platform must have its upper surface perfectly level and it must remain so for an 
indefinite time, otherwise the ants will take up their abode between the cage and platform rather than in the cage itself. The platform is therefore made of two pieces of even, seasoned cypress $7 / 8$ inches thick, screwred together with numerous screws and with the grain of the two pieces at right angles to each other. On this platform the cage rests without fastenings of any kind. The cover (5) is constructed of two pieces of cypress in the same manner as the platform, but in addition has an iron handle attached to its upper surface and has a piece of felt glued to its under surface so that, when it is placed upon the cage proper, all light is excluded except at the entrance. The cover is of the same outside dimensions as the cage itself. To insure the platform remaining level it is often necessary to make

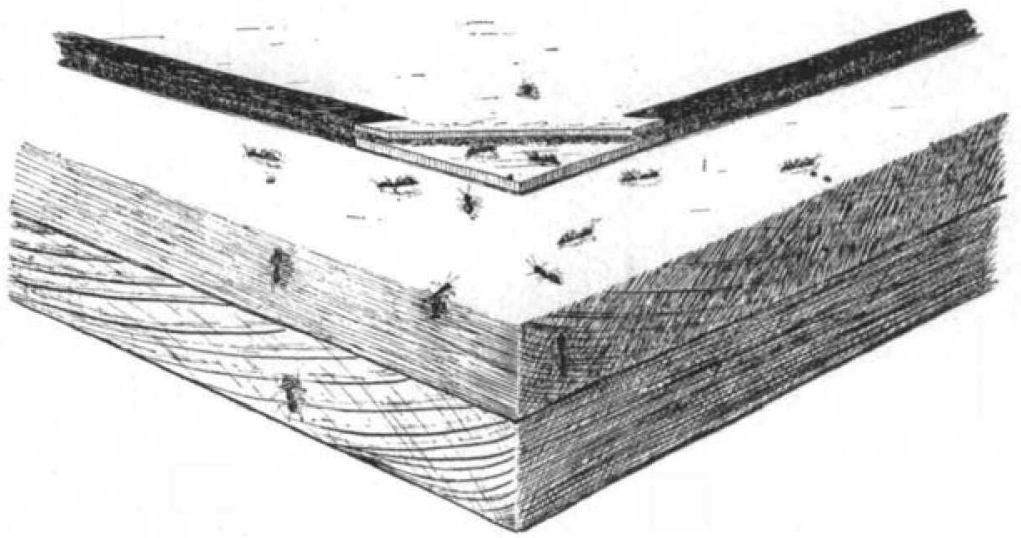

Fig. 3.-Fntrance of formicary shown in figures 1 and 2 (figs. 1,2 and 3 from original drawiugs by Miss Ethel Hutson).

the base of two pieces in the same manner as the platform, or to nail strips across it at right angles to the grain. Both platform and base are attached to the standard by long screws with heads countersuml. Food is furnished by placing it on a piece of cardboard at any point on the cover or platform. The base stands in rumoing water, as explained below. This type of cage permits the ants to leave their nest within the cage and to forage over the platform, cover and stand in natural fashion, but their escape from the stand is prevented by the very natural barrier of water which they find when they approach the bottom of the standard. It is not possible for them to conceal larvw or eggs where the observer cannot find them and they cannot bring in larve or pupæ from outside sources, to the annoyance and vexation of the student.

While the ants are very fond of sweets we have found that sweets 
alone will not suffice for food indefinitely. Animal food is also required and we find that by supplying the colonies with a "balanced ration" of honey and fresh beef or veal, they will work in a perfectly natural manner for many months without other food.

The problem of confining the ants to the cage and its stand was not so easily solved. We first tried Sir John Lubbock's method of placing a moat of glycerine or water about the stand, but both liquids dried too quickly and were effective for only a few hours. Recourse was had to the proverbial chalk line without success. Bands or ditches of kerosene, crude oil, tar, oils of sassafras and citronella, tree tanglefoot, zenoleum, naphthaline, coal tar disinfectants, whaleoil soap, sharp-edged tin and fur were all failures. Certain.powerful odors, such as those of zenoleum, sassafras and citronella, act as repellents temporarily, but after a few hours of evaporation are no longer effective. Ordinarily these ants will not cross bands of cotton tape which have been impregnated with a saturated solution of corrosive sublimate and dried, but when attempting to leave an area to which they have been confined by this means they are much more persistent in crossing it.

Water with a film of whale-oil soap on it acted as a repellent for a few hours only, while a film of kerosene upon water merely afforded a convenient floor upon which the ants could travel. The difficulty in confining the workers with any liquid or mucilaginous substance lies in the fact that they are exceedingly light ${ }^{2}$ and sticky substances shortly harden on the surface so that the workers are supported. The surface film of clear water is in fact almost strong enough to support a worker not loaded. It is not unusual to see an ant alternately walking and swimming in crossing a narrow ditch of water which has been standing for a few hours. Minute dust particles collecting upon standing water shortly form a film upon which the workers pass with ease. Perfectly fresh water therefore served to confine the colonies to their cages and at first our observations were made upon colonies in cages which were standing in dishes of water. This, however, necessitated frequent changing of the water, and observations were often brought to an abrupt finish by other duties preventing the change of water in the vessels at the right time.

Our next step was to construct a small building, $10 \times 30$ feet, equipped with benches having upon them galvanized iron trays $21 / 2 \times 12$ feet, 4 inches deep. In these trays the cages are placed and by suitable connections running water 2 inches deep is kept

The average weight of one worker is 0.0002077 grams. 
passing through the trays day and night. As the ants will not voluntarily enter running water this method has worked admirably. The building in which this work is carried on is shown in Plate 6 . The iron trays and ant cages are shown upon the right, with work tables, chemicals, etc., on the left. The building is equipped writh electric lights and extension lights for night examination, in addition to gas, and a combined hygrograph and thermograph records the temperature and humidity of the room at all times. For convenience we have called this special building a "formicarium"-which the office boy invariably confuses with "auditorium" and "natatorium." Plenty of windows insure full ventilation at all seasons; and to avoid abnormally high temperatures in summer a second or accessory roof, 2 feet above the main roof, breaks the rays of the sun and shades the building proper. The building has also proven a convenient insectary for the breeding of other insects. The Argentine ant possesses a marked proclivity for attacking all insects which one has under observation, and all breeding experiments in cages, no matter what the insect, must be protected from the ants. The trays of runaing water therefore serve to keep the ants away from general cage experiments, as well as to confine the ants to the cages in which they themselves are being studied.

It may be mentioned that Prof. C. W. Woodworth of California visited this "formicarium" in the summer of 1908 and so pleased was he with the cages and the plumbing arrangements of the formicarium that he returned to California and prepared a similar outfit for the study of the Argentine ant there.

\section{Establishing Colonies for Study}

To establish a colony in one of the artificial formicaries or cages is comparatively easy. It is only necessary to secure a fertile queen from some thriving outdoor colony and place her on the stand, first placed in water, together with any desired number of workers which have been captured by attracting them to a sweetened sponge or piece of fresh meat. Any lot of workers will accept any queen and vice versa. When queen and workers are thus placed upon the cage and its stand, they usually, after a few hours, take up their abode in the nest proper. At first we experienced some difficulty in preventing them from collecting beneath the stand, but it was presently found that if a little dirt be removed from another colony and placed in the entrance of the new formicary the ants would enter at once and adopt it as a suitable home. After the establishment of such colonies the queen usually commences egg deposition in from 6 to 48 hours. 
By establishing colonies in this manner, without immature stages present, it is easy to observe the daily rate of egg deposition, the incubation period of the eggs, and the duration of the larval and pupal stages. In some of the records given below single individuals have been kept under observation from deposition of the egg, through larval and pupal stages, to the adult. In other cases the time from deposition of the first egg until hatching of the first larva was assumed to be the period of incubation, date of hatching of first larva to formation of first pupa the duration of larval period, etc.

\section{The Queen}

The deälated queen is well illustrated at c. figure $4 .^{3}$ The deälated queen measures from 4.5 to $5 \mathrm{~mm}$. in length and queens measuring $6 \mathrm{~mm}$. in length are not uncommon. It should be remarjed here that during egg laying periods the abdomen is much larger and longer than shown in the drawing. Normally the abdomen extends well beyond the tarsi of the hind legs. Unfortunately, a drawing cannot show the delicate silky pubescence of the queen's body and in life she is a far more beautiful creature than one would imagine from the drawing, correct though the latter is in anatomical detail.*

The credit for first discovering and recognizing the queens of this species seems to belong to Mr. E. Baker, formerly superintendent of Audubon Park, New Orleans, and Prof. R. E. Blouin, formerly in charge of the Audubon Park Experiment Station. Queens found by them in August, 1905, are still in the writer's collection. ${ }^{5}$ If Mr. Titus was familiar with the queens he evidently failed to mention it in his interesting account of this species. ${ }^{\circ}$

The rate at which the queen deposits eggs varies with the prevailing temperature and egg deposition is suspended entirely at low temperatures. In the artificial formicaries, already described, the num-

\footnotetext{
"The writer is under obligations to Dr. W. M. Wheeler for a critical examination of the drawings shown in figure 4 prior to their engravure.

"For a detailed description of the queen, see Jovrnal of Economic EntoMOLOQY, I, p. 29.

r Following is the letter from Professor Blouin, announcing the finding of these queens:

Audubon Park, New Orlenns, La., August 21, 1905.

Mr. Wilmon Newell, Shreveport, La.

Dear SIr: I enclose you a few specimens of the queen ant of the species recently investigated here by Mr. Titus, named by him the New Orleans ant, ol Iridomyrmex humilis Mayr. These were collected by Mr. D. Baker, Supt. of Audubon Park, in his nursery right close to us.
}

'Bulletin 52, Bur. of Entomology, p. 79.

(Signed) R. E. BLoUIN. 
ber of eggs laid each day varies from one or two to as many as fifty or sixty. Thirty per day is not far from the normal number in warm weather when the food supply is abundant. It appears probable, however, that the queens deposit much more rapidly in large colonies, although, from the nature of the case, this cannot be verified by direct observation. Egg deposition becomes very slow, or ceases entirely, when the daily mean temperature falls below $68^{\circ} \mathrm{F}$.

Practically all queens under observation have shown a disposition to suspend egg deposition entirely for longer or shorter periods,
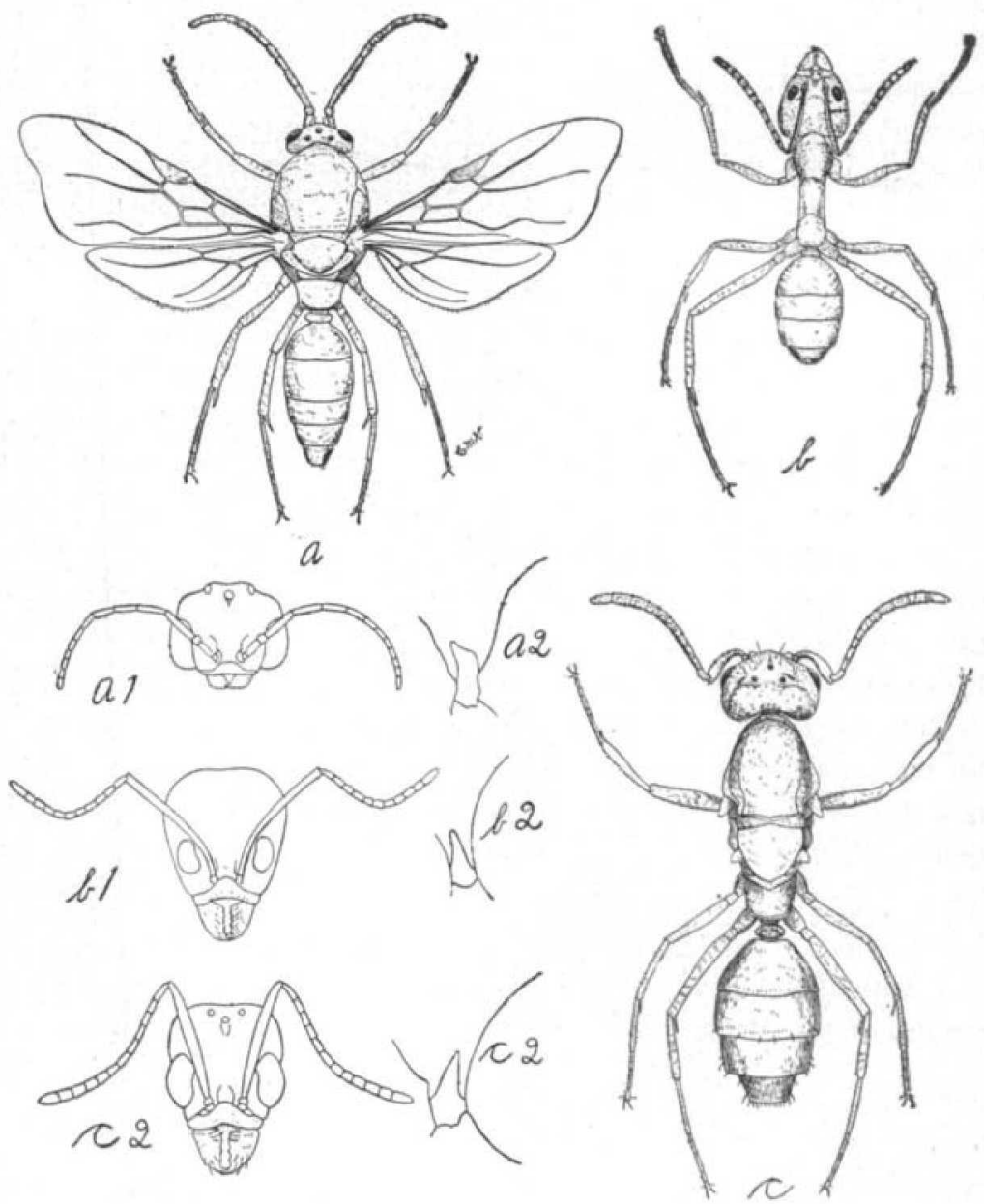

Fig. 4.-The Argentine ant: $a$, adult male; $a 1$, head of male; $a 2$, petiole of male ; $b$, worker ; $b 1$, head of worker ; $b 2$, petiole of worker ; $c$, fertile queen ; $c \%$, head and petiole of queen; all greatly enlarged (from original drawings made under the author's direction by Miss C. M. King). 
even when such "off" periods cannot be accounted for by low temperatures.

Fertile queens confined in test tubes without accompanying workers will often deposit a few eggs upon the walls of the tubes, but we have been totally unable to get colonies established by confining queens in artificial formicaries without workers accompanying them. This failure has not been due to any need of workers to feed or care for the queen, since she can feed herself from a supply of honey or sugar as readily as can a worker. Ordinarily, she attends to her own toilet and it is doubtful whether she is in reality "attended" by the workers in the sense that queen bees are attended.

Fertile queens do not confine themselves to the formicaries, either natural or artificial. Isolated deälated queens are not infrequently found wandering about buildings by themselves and, while the queens in artificial formicaries ordinarily stay within the nest proper, they have at times been seen outside of it. The finding of deälated queens wandering about, coupled with the fact that workers readily accept a queen from any source, seems to indicate that new colonies may sometimes be established in nature by workers associating with such wandering queens. This probable method of colony formation is quite distinct from the pronounced division, or "divisional migration," which is referred to on a subsequent page.

All immature stages of the queen are as yet unknown. In the two seasons during which colonies have been under almost daily observation, not a single queen has been developed in any of the artificial formicaries, though males have been developed in abundance.

Virgin queens should be easy to discover in areas heavily infested by the species but such is not the ease; nor have we been able to detect any of the virgin queens when the males were flying in abundance. Only three virgin queens have thus far come under our observation. These were found on April 21, 1908, by Messrs. Rosenfeld and Barber, two of my assistants, in the course of examining a very large colony which had been driven from a low marshy area by the rising waters of the Mississippi River.

\section{The Worker}

The worker measures from 2.25 to $2.75 \mathrm{~mm}$. in length and is well illustrated in figure 4, $b$. As with the queen, the abdomen extends to about the tarsi of the hind legs when the worker is active or engaged in feeding. The abdomen is capable of considerable distension, and when the worker is fully engorged with syrup or other liquid the chitinous plates of the abdomen are forced apart, rendering 
the connecting membranes distinctly visible. The writer has often noticed workers returning from their attendance upon plant lice with abdomens so distended that they looked like little drops of silvery liquid. Particularly is this appearance presented when the returning workers are viewed with a strong light beyond them.

As already stated there is but one caste among the workers. In a large colony there seems to be something of a division of labor, certain ones engaging in foraging, others in nursing and still others in excavating or sanitary work. However, any individual worker can assume the duties of any other and does do so when exigencies demand. Worker callows, barely hardened into mature adults, go forth in search of food and the hardened veterans of many months' service seem to make as efficient nurses as even the youngest.

The workers are particularly long-lived. A colony of about seventy workers was made queenless and broodless on July 8, 1908 . By October 10th the number of workers had become reduced to about forty and some of the original ones survived until February 25, 1909; a period of $61 / 2$ months. But for the fact that many of these workers met death accidentally a longer period of survival would doubtless have been recorded.

\section{The Égg}

The egg, which is to produce a worker, is elliptical, about $.2 \mathrm{~mm}$. wide by $.3 \mathrm{~mm}$. long. It is pearly white, lustrous and without markings (See Plate 7, A). As time for hatching approaches it loses its brilliancy and the surface takes on a duller appearance. This is not sufficiently pronounced and uniform, however, to be taken as a safe guide to immediate hatching. The egg membrane is exceedingly thin, so thin in fact that when the embryo has taken on the larval shape, the membrane not infrequently adapts itself in a way to the general contour of the enclosed embryo, thus making it very difficult to distinguish between eggs and just-hatched larve.

Some care of the egg by the workers seems essential to complete embryonic development. Eggs deposited in test tubes by isolated queens have gone through a portion of the embryonic development, but we have not been successful in getting them to hatch. This may be due in part to the ease with which the delicate embryos can be in. jured in handling and to the fact that when placed on glass condensing moisture may retard or stop development.

\section{Incubation}

The eggs, after deposition by the queen, hatch in from 18 to 55 days, according to the prevailing temperature. The longer periods 
are doubtless accounted for by embryonic development being entirely suspended during cool weather, and it is not impossible that the viability of eggs may be entirely destroyed by a temperature as low as 25 or $30^{\circ}$, but on this point we are as yet undecided.

The period of incubation has been determined, ordinarily, by placing a queen and workers, but no immature stages, in an artificial formicary and then noting the time from deposition of the first egg to appearance of the first larva. This period was assumed to be the real period required for incubation. In other cases, single groups. of eggs have been lept under constant observation throughout the entire period of incubation. The following table shows the variation in development at different seasons, together with the average daily mean temperatures prevailing:

TABLE I

Duration of Egg Stagle at Different Seagong-Worker

\begin{tabular}{|c|c|c|c|c|c|}
\hline $\begin{array}{c}\text { Record } \\
\text { No. }\end{array}$ & From & To & Days. & $\begin{array}{l}\text { Average dally mean } \\
\text { temperature during } \\
\text { period. }\end{array}$ & $\begin{array}{c}\text { Average dally mean } \\
\text { humidity. }\end{array}$ \\
\hline $1 . . \cdots$ & Oct. 1,1907 & Nov. 15,1907 & $45 \frac{1}{k}$ & * & 1 \\
\hline s........ & Dec. 22,1907 & Feb. 14, 1908 & 56 & * & 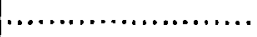 \\
\hline $4 \ldots$ & Mar. 14,1908 & April 9,1908 & 27 & $70.3^{\circ} \mathrm{F}$ & $70.2 \%$ \\
\hline 6... & May 1,1908 & May 23,1908 & 23 & 74 & 68.9 \\
\hline $7 \ldots \ldots \ldots$ & Joly 20,1908 & Aug. 10, 1908 & 22 & 81 & 82.9 \\
\hline 8........ & July 25, 1908 & $\operatorname{Aug} .12,1908$ & 19 & 81 & 81.5 \\
\hline & & Average & 32 & & \\
\hline
\end{tabular}

\section{The Larva}

The larva when first hatched is not distinguishable from the egg without the assistance of a maguifying glass. For a time after hatching the body is severely curved, the cephalic end being almost in touch with the caudal end, but as development progresses the larva assumes more and more of a straight form. The curvature is not entirely lost, however. A recently hatched larva, measured with the compound microscope and eye-piece micrometer, measured $.49 \mathrm{~mm}$. long by .32 wide. The fully grown larva (workers) average $1.7 \mathrm{~mm}$. long ly .66 mm. wide. The largest one under our observation measured $1.87 \mathrm{~mm}$. by $.765 \mathrm{~mm}$.

*Cages kept in office; record of exact temperatures not available. The ba]ance of the records were made in the "formicarium" and the recording instruments kept in the same raom with the cages, hence the temperature and humidity records are correct for the exact location of the eggs under observation. 
The larve are fed often by the attending workers upon regurgitated, and presumably predigested, food. There is nothing in the appearance or actions of the workers which do the feeding to indicate that they are different from those which perform other duties, or that they are assigned to the particular and exclusive duty of being nurses. The feeding of the larva has several times been observed under a magnifying glass and is as follows: The larva ordinarily lies upon its side or back. The attending worker approaches from any convenient direction, usually from one side or from the direction in which the head of the larva lies and, spreading her mandibles, places them over the mouth-parts of the larva which are slightly extruded. The tongue of the worker is also in contact with the larval mouth. While the worker holds body and mandibles stationary a drop of light-colored, almost transparent fluid appears upon her tongue. This fluid disappears within the mouth of the larva, but it cannot be ascertained to what extent the larval mouth-parts are moved during the operation, owing to their being obscured from view by the mandibles and head of the attending worker. Slight constrictions of the larval abdomen during feeding are sometimes noticeable, at other times not. The time required for feeding a single larva varies from 3 to 30 seconds, depending doubtless on the hunger of the "baby."

The workers proffer food to, or at least inspect, each larva, for the worker doing the feeding will place her mandibles to the mouth of one larva after another, feeding those which seem to require it.

Both larve and pupæ are groomed or licked with the tongues of the workers; thus are they ever kept in a state of absolute cleanliness.

The most pronounced increase in size of the larvæ occurs during the first five days after hatching; after that it is relatively slower. As the larva increases in size the contents of the alimentary canal, dark in color, can be. seen through the walls of the abdomen.

Just prior to transformation into pupa, the larva takes on a rather characteristic appearance, which if it were more distinct, would justify characterization as the "pre-pupal" stage. In this stage the cephalic and thoracic portions of the larva become markedly smooth and shining, with segmentation indistinct or absent. At the same time the line of demarcation between thorax and abdomen becomes more distinct and the contents of the alimentary canal appear to be shifted nearer to the caudal end than in the larva proper. The mouth-parts, indistinct in the larval stage, now appear more prominent. The difference between larval and pre-pupal stages is by no means pronounced, but with practice one can predict the approaching transformation to pupal stage by it with reasonable accuracy. 
The duration of the larval period has been determined by observation in the artificial nests in the same manner as the incubation period, already described.

The following table shows the duration of the larval period at different seasons :

TABLE II

DURATION OF LARVAL STAGE AT DIFFERENT SFAgONS-WORKER

\begin{tabular}{|c|c|c|c|c|c|}
\hline $\begin{array}{l}\text { Record } \\
\text { No. }\end{array}$ & From & To & Days. & $\begin{array}{c}\text { Average daily mean } \\
\text { temperature during } \\
\text { period. } \tau^{7}\end{array}$ & $\begin{array}{c}\text { Average daily mean } \\
\text { humidity. }\end{array}$ \\
\hline $1 \ldots \ldots \ldots$ & Nov. 16,1907 & Jan. 15,1908 & 61 & $62.2^{\circ} \mathrm{F}$ & \\
\hline $6 \ldots . . .$. & Feb. $\quad 5,1908$ & April 1,1908 & 57 & 62.2 & $71.9 \%$ \\
\hline $8 \ldots \ldots \ldots$ & Feb. $\quad \overline{5}, 1908$ & April 1,1908 & 57 & 62.2 & 71.9 \\
\hline $10 .$. & Feb. 15,1908 & Mar. 28, 1908 & 43 & 62 & 72 \\
\hline 3.... & Feb. 29,1908 & Mar. 26, 1908 & 27 & 67 & 73 \\
\hline 9......... & April 10, 1908 & April 24, 1908 & 15 & 76.6 & 75.3 \\
\hline $7 \ldots \ldots \ldots$ & April 12, 1908 & April 25, 1908 & 14 & 76.1 & 75.2 \\
\hline $2 \ldots \ldots \ldots$ & July 19,1908 & Aug. 1,1908 & 14 & 80.5 & 82 \\
\hline $11 \ldots \ldots$ & Aug. 19,1908 & Aug. 27,1908 & 15 & 81.7 & 71.7 \\
\hline \multirow[t]{2}{*}{$4 \ldots \ldots$} & Sept. 4,1908 & Sept. 14, 1908 & 11 & 81.1 & 73.6 \\
\hline & & Average & 81 & & \\
\hline
\end{tabular}

\section{The Pupa}

The pupa immediately after transformation from the larval stage is pure white, without markings, except that the compound eyes are prominent as jet black spots upon the head. The pupa is slightly larger than the grown larva, the average length being about $2 \mathrm{~mm}$. The head is by far the most prominent portion. A pupa measuring $2.04 \mathrm{~mm}$. in length was found to have a head $1.19 \mathrm{~mm}$. in length (dorso-ventral diameter) while the thorax and abdomen measured .51 and $.561 \mathrm{~mm}$. respectively. The pupæ are shown in Plate 7, $b$ and $d$.

As time for transformation to adult approaches the pupa changes to a creamy color, then through a light brown to a dark brown, the latter shade being practically identical with the body color of mature workers. The time of these changes varies with the duration of the pupal stage, but the following record of changes in color of a pupa which occupied a full twenty days from larva to adult (callow), is near the average:

'We have not attempted to give the accumulated effective temperature necessary for the development of different stages, as we are not satisfied as to the critical point from which it should be computed. It is doubtless higher than $43^{\circ} \mathrm{F}$. 
Ist to 17th day-Pupa pure white, except componnd eyes.

18th day-Turned to a light creamy yellow.

19th day-Became a light brown.

20th day - The brown color deepened.

21st day-Reached teneral stage.

In some colonies there is more or less of an indistinct sorting of the immature stages, pupx being placed in one portion of the nest and larvæ in another. This tendency is not perceptible in many colonies and is usually most noticeable in very large colonies.

The duration of the pupal stage has been determined in the manner already described for the incubation and larval periods. The range of pupal development is shown in the following table:

TABLE III

Duration of Pupal State, Individual Workers, 1908

\begin{tabular}{|c|c|c|c|c|c|}
\hline $\begin{array}{c}\text { Record } \\
\text { No. }\end{array}$ & From & To & Days. & $\begin{array}{c}\text { Average daily mean } \\
\text { temperature during } \\
\text { period. }\end{array}$ & $\begin{array}{l}\text { Average dally mean } \\
\text { humidity. }\end{array}$ \\
\hline $1 \ldots \ldots$ & $\operatorname{Jan} .21$ & Feb. 14 & 25 & $56.5^{\circ} \mathrm{F}$ & $68.8 \%$ \\
\hline $2 \ldots \ldots \ldots$ & Mar. 14 & Mar. 27 & 14 & 67.5 & 71.8 \\
\hline $5 \ldots \ldots$ & Mar, 26 & Apr. 11 & 17 & 73.8 & 68.9 \\
\hline $6 \ldots \ldots$ & Маг. 30 & Apr. 14 & 16 & 73.8 & 70.2 \\
\hline 3....... & Apr. 5 & Apr. 15 & 11 & 76 & 73.5 \\
\hline $10 \ldots \ldots$ & Apr. 5 & Apr. 18 & 14 & 76.3 & 74 \\
\hline $7 \ldots \ldots \ldots$ & Apr. 5 & Apr. 20 & 16 & 76.7 & 74 \\
\hline $8 \ldots \ldots \ldots$ & Apr. 8 & Apr. 23 & 16 & 76.6 & 74.5 \\
\hline $9 \ldots \ldots \ldots$ & Apr. 25 & May 18 & 19 & 71 & 68.6 \\
\hline $11 .$. & Apr. 26 & May 14 & 20 & 71.2 & 61.4 \\
\hline $4 \ldots$ & Aug. 1 & Aug. 11 & 11 & $82+2$ & 80 \\
\hline $12 \ldots$ & Aug. 6 & Aug. 16 & 11 & 83 & 74.8 \\
\hline $18 \ldots \ldots$ & Aug. 10 & Aug. 20 & 11 & 82.8 & 70.7 \\
\hline $14 \ldots \ldots$ & Aug. 28 & Sept. 7 & 11 & 81.4 & 71 \\
\hline & & Average & 15 & & \\
\hline
\end{tabular}

\section{The Callow or Teneral Stage}

During the last few hours of the pupal stage the legs, mouth-parts and antennx become more prominent and the pupa is assisted in its transformation by the workers, who attempt to straighten out the legs and antenna. We are convinced that there is a very thin transparent membrane or slin surrounding the pupa, which is shed at time of transformation but its existence is difficult to establish satisfactorily. 
Immediately after transformation the young worker is colorless, almost transparent, but is otherwise identical in appearance with fully matured workers. To this stage, following the custom of some authors, we apply the term "callow." The callow is at first very clumsy and walks with uncertain steps and staggering gait, reminding one much of a worker bee just emerged from the brood comb. During this stage the workers seem still to feel a responsibility for the callow's welfare, for upon the colony being disturbed the callows, like larve and pupæ, are unceremoniously grabbed up by the workers and hustled to a place of safety.

The body of the callow deepens in color quite rapidly and in from 48 to 72 hours after transformation from the pupa becomes indistinguishable from other adult workers.

\section{Time Required for Complete Development}

By adding together the minimum periods required for the development of eggs, larve and pupæ, as given in Tables I, II and III, we find that at least 41 days are required for development from egg to adult and in a similar manner addition of the maximum periods gives 141 days as the maximum time required.

From the tables also it is seen that the average period of incubation for the eggs is 32 days, for development of the larva 31 days and for maturing and transformation of pupa to adult 15 days. By adding together these averages we arrive at 78 days as the average period of development. This of course cannot be termed the time required for the development of a generation, since workers do not reproduce and the term "generation" can be used only in referring to the succession of queens.

\section{The Male}

The appearance of the adult male is well illustrated in figure $4, a$. The males average about 2.8 to $3 \mathrm{~mm}$. in length. The most noticeable feature about them is the manner in which the thorax is enormously developed. The abdomen is relatively small and the head short and blunt. The shape of the head alone permits distinction between the male and virgin (winged) queen without the aid of a glass.

The normal time of appearance of the males in the colonies is in spring, but the appearance of a relatively small number in autumn is not uncommon. During mid-winter and mid-summer none are found. The males have been bred in the artificial formicaries in large numbers, hence abundant opportunity has been afforded to study their appearance and habits. The following account of their appearance in 
one colony under observation is typical: In Cage 1 the first male pupa made its appearance on April 11, 1908, and by April 15 the male pupæ were numerous. The first of these reached maturity on May 1st. By May 11th the adult males in the colony numbered 11 and on this date some of them essayed a flight. For several days following daily flights were made, most of them terminating ignominiously in the galvanized iron trays of water.

On May 14th the male pupæ in this colony were still appearing abundantly and they continued to appear, at a deceasing rate, until June 27th. By July 8th but one male remained in the colony and this one disappeared by July 22d.

Examinations of the outdoor colonies during May showed males present in practically all of them. Flights out of doors were common during May but we were unable to find any virgin queens among the flying males.

In the autumn males are found in but a small percentage of the outdoor colonies and they rarely appear in the artificial formicaries. In December of 1907 one of my assistants found males exceedingly abundant in a single colony, while in another colony an assistant noticed them constantly present during all of November and December of the same year. In October of 1908 a few males were found in a single outdoor colony. We have found no virgin queens in the autumn.

The eggs which produce males are indistinguishable from those which produce workers and we have found no way to separate the male-producing larvæ from the worker-producing larvæ until just prior to pupation. The male larvæ grow to a somewhat larger size, on the average, than do the worker larvæ and it is thus possible to predict with some degree of certainty which of grown larve will transform to males and which to workers. As soon as transformation to pupa talies place there is no further confusion. The male pupa is fully $50 \%$ larger than the worker pupa and has, by comparison, an enormous thorax. The male pupæ vary in length from 2.78 to 3.23 $\mathrm{mm}$., with an average length of $3.04 \mathrm{~mm} .^{8}$ As the average length of the thorax alone is $1.9 \mathrm{~mm}$., it is at once seen what a relatively large part of the body it constitutes. The male pupa is shown in the center of Plate 7.

When first transformed from the larval stage the male pupa is pure white, with exception of the compound eyes, which are faintly tinged with brown. Gradually the color of the compound eyes deepens and

'From measurements of 10 specimens by Mr. Arthur H. Rosenfeld. 
the ocelli become visible as minute dark spots upon the head. The male pupa, like the worker pupa, passes through gradations of creamy yellow, light brown and dark brown to almost black before transforming to the adult stage. The color reached by the male pupa just prior to transformation is much deeper than that attained by worker pupæ. The males are assisted in their transformation to the adult stage by the workers, and the pupal skin, or at least a portion of it, is worked backwards to the tip of the abdomen and there shed entirely. Within a few hours after transformation the wings of the male become fully expanded. The following table shows the duration of the male pupal stage at different seasons:

TABLE IV

Duration of Pupal State, Individual Males, 1908

\begin{tabular}{|c|c|c|c|c|c|}
\hline $\begin{array}{l}\text { Record } \\
\text { No. }\end{array}$ & From & To & Days. & $\begin{array}{c}\text { Average daily mean } \\
\text { temperature during } \\
\text { period. }\end{array}$ & $\begin{array}{l}\text { Average daily mean } \\
\text { humldity. }\end{array}$ \\
\hline $1 \ldots \ldots \ldots$ & April 11 & May 1 & 194 & $73.6^{\circ}$ & $69.8 \%$ \\
\hline 2. & Aprll 14 & May 4 & $20 t$ & 73.6 & 68.6 \\
\hline g........ & April 14 & May 4 & $20 \frac{1}{2}$ & 78.6 & 68.6 \\
\hline 4.. & April 17 & May 10 & 24 & 72.8 & 67.3 \\
\hline $7 .$. & April 17 & May 10 & 24 & 72.8 & 67.3 \\
\hline 8....... & Aprll 18 & May 11 & 24 & 72.2 & 66.7 \\
\hline $9 . \ldots \ldots$ & April 18 & May 18 & $2 \hat{0}$ & 72.8 & 66.5 \\
\hline 6.. & April 20 & May 13 & 24 & 71.8 & 65.8 \\
\hline \multirow[t]{2}{*}{$6 \ldots \ldots \ldots$} & Sept. 24 & Oct. 21 & 28 & 70.5 & 67.6 \\
\hline & & Average & $28 \frac{1}{2}$ & & \\
\hline
\end{tabular}

\section{Formation of New Colonies}

Reference has already been made to the possibility of new colonies being formed by workers associating themselves with wandering or migratory (?) fertilized queens. However, the more common method of colony formation is a very different process. In the autumn months there is a marked tendency for colonies to unite and seek dry sheltered situations, such as masses of leaves, straw, etc., in which to pass the winter. Comparatively few colonies attempt to pass the winter in underground nests unless these are situated in protected places, as under buildings, boards, vegetation, etc. The large winter colonies frequently contain hundreds of queens. With the approach of warm weather small colonies, varying in size from one queen and a dozen or two workers to a half dozen queens and several hundred workers, migrate out from the large over-wintering colonies and establish them- 
selves in new situations, by preference in soft earth. This spring movement is sufficiently pronounced to be termed a migration, and from its nature it seems best to call it a "divisional migration." In the spring of 1908 it was noticed to occur in the early part of March. The present season this movement began as early as February 13th. This spring division of large colonies into small also explains why large colonies are the rule in autumn and small colonies the rule in spring.

\section{Scientific Notes}

A Remedy for House Fleas.-In the latter part of last May (1908) I mored into a new house that had not been preriously occupied. No carpet was used and being summer only a few rugs were placed on the floors. A part of the household consisted of a collie dog and three Persian cats. Very soon the fleas appeared, the dog and cat flea, Ctenocephalus canis. I did not count them and I can't say whether they numbered a million or only a hun. dred thousand. On arising in the morning and stepping on the floor one would find from three to a dozen on the ankles. The usual remedies for fleas are either drastic or somewhat unsatisfactory. The drastic one is to send the animals to the institutions, where they are asphyxiated, or take the other advice, "Don't keep animals."

I tried mopping the floors with a rather strong solution of creolin but it did little good: Previous experience with pyrethrum was not very satisfactory. Knowing the volatility of naphtbaline in warm weather and the irritating character of its vapor led me to try it. I took one room at a time, scattered on the floor five pounds of flake maphthaline and closed it for twenty-four hour's. On entering such a room the naphthaline vapor will instantly bring tears to the eyes and cause coughing and irritation of the air passages. I mention this to show how it acts on the fleas. It prored to be a perfect and effectual remedy and very inexpensive, as the naphthaline could be swept up and transferred to other rooms. So far as I am concerned the flea question is solved and if I have further trouble $I$ know the remedy. I intend to keep the dog and the cats.

HeNRY SKINNER, M. D.

Kerosene Emulsion for Terrapin Scale. A number of soft maples, literally loaded with Eulecanium nigrofasciatum Perg., were sprayed April 25, 1908, with a lime-sulfur wash, using $20 \mathrm{lbs}$. of lime and $15 \mathrm{lbs}$. of sulfur. The spray was applied hot and very thoronghly, about 10 gallons being used for each tree having a trunk diameter of 8 to 10 inches. Similar trees were then sprayed with a stock solution of kerasene emulsion, made seven months before and diluted to make a $20 \%$ solution. Many of the twigs with a diameter of over $1 / 2$ an inch were completely covered with scale. The temperature at the time of application was about $60^{\circ} \mathrm{F}$. and the leaves were nearly the size of a fifty cent piece. About 45 minutes after the oil application there was a terrific rain storm, lasting 15 to 20 minutes. The lserosene emulsion killed very few leaves, while the lime-sulfor wash did no injury. 